\title{
Community Size as a Factor in Health Partnerships in Community Parks and Recreation, 2007
}

Laura L. Payne, PhD; Jo An M. Zimmermann, PhD; Andrew J. Mowen, PhD; Elizabeth OrsegaSmith, PhD; Geoffrey C. Godbey, PhD

Suggested citation for this article: Payne LL, Zimmermann JA, Mowen AJ, Orsega-Smith E, Godbey GC. Community Size as a Factor in Health Partnerships in Community Parks and Recreation, 2007. Prev Chronic Dis 2013;10:120238. DOI: http://dx.doi.org/10.5888/pcd10.120238 国.

PEER REVIEWED

\section{Abstract}

\section{Introduction}

Although partnerships between park and recreation agencies and health agencies are prevalent, little research has examined partnership characteristics and effectiveness among communities of different sizes. The objective of this study was to determine whether park and recreation leaders' perceptions of partnership characteristics, effectiveness, and outcomes vary by community size.

\section{Methods}

A web-based survey was completed in 2007 by 1,217 National Recreation and Park Association members. Community size was divided into 4 categories: very small, small, medium, and large. Questions measured agencies' recognition of the need for partnerships, their level of experience, and the effectiveness and outcomes of partnerships.

\section{Results}

Larger communities were significantly more likely to recognize the need for and have more experience with partnerships than smaller communities. Very small and large communities partnered significantly more often with senior services, nonprofit health promotion agencies, and public health agencies than did small and medium ones. Large and small communities were significantly more likely than very small and medium communities to agree that their decision making in partnerships is inclusive and that they have clearly defined goals and objectives. Large communities were significantly more likely than very small communities to report that their partnership helped leverage resources, make policy changes, meet their mission statement, and link to funding opportunities.

\section{Conclusion}

Community size shapes partnership practices, effectiveness, and outcomes. Very small communities are disadvantaged in developing and managing health partnerships. Increasing education, training, and funding opportunities for small and rural park and recreation agencies may enable them to more effectively partner with organizations to address community health concerns.

\section{Introduction}

Community park and recreation agencies are stakeholders in addressing health issues such as physical inactivity, obesity, and chronic disease and are partners in the healthy communities' movement. Interorganizational partnerships can facilitate health behavior change that prevents chronic disease. Kernaghan (1) defined partnerships as relationships that involve a sharing of power, work, support, or information with others for the achievement of joint goals or mutual benefits. Partnerships are important for park and recreation agencies given health, social, and economic concerns of the nation $(2,3)$. Bors and colleagues $(4)$ emphasized the need for partnerships to address public health issues because various disciplines and groups can accomplish more together than separately. Most model health promotion programs (eg, Centers for Disease Control and Prevention's Action Communities for Health, Innovation, and Environmental Change [ACHIEVE] Initiative [5]) require formal partnerships between health and park and 
recreation agencies to achieve their goals. Furthermore, in a study of North Carolina park and recreation directors, respondents indicated that one of their highest priorities was to develop more interagency health partnerships (6).

Health partnerships in parks and recreation have become more prevalent in the past 20 years as agencies try to optimize resources with limited budgets. Although the importance of health partnerships is widely recognized $(4,6)$ little is known about the nature and extent of partnerships between park and recreation agencies and health agencies. One study found that health partnerships were common across the park and recreation field; approximately $90 \%$ of agencies report some type of partnership (7). Health partnership participation was found to be related to the size of the organizational budget and population of the community served. Agencies that served larger populations were more likely to engage in formal collaborations. Therefore, the purpose of this national study was to determine whether perceptions of partnership characteristics, effectiveness, and outcomes vary by community size.

\section{Methods}

\section{Data collection}

This study is part of a larger cross-sectional project that consisted of an online survey and in-depth interviews of park and recreation managers. Data were collected by using a web-based survey, and Pennsylvania State University's institutional review board approved this study. The National Recreation and Park Association (NRPA) membership database was used to identify directors or senior managers (4,388 of 21,152 members met these criteria). Investigators reviewed the database to ensure that only 1 person from each member agency was invited to participate in the survey. NRPA is a professional organization whose mission is to advance parks, recreation, and environmental conservation efforts that enhance the quality of life for all people.

A presurvey letter was e-mailed to the sample on October 1, 2007, to announce the online survey. Ten days later, a second e-mail was sent with a cover letter and a link to the survey. After the first survey invitation, follow-up e-mails were sent to nonrespondents every 10 days for 1 month. Within the list of 4,338 NRPA members, 558 e-mails were undeliverable, reducing the sample to 3,780. Of these recipients, 1,217 completed the questionnaire, a response rate of $32 \%$. Individuals contacted could opt out of the survey, take it and stop at any time, or complete the survey. Respondents concluded their participation when they finished the survey (which took 10-15 minutes) and were entered into a drawing for a small retail gift card. Because the focus of this study was local, public community park and recreation agencies (eg, municipal, township, county), state and national parks, military recreation, and nonprofit agencies (eg, YMCAs) were excluded from subsequent analysis, resulting in 1,089 usable surveys. To assess the potential threat of nonresponse bias in the sample, a random sample of 100 nonrespondents was contacted by telephone and e-mail and answered several questions. Results indicated that respondent characteristics and agency partnership practices reflected those reported by nonrespondents regarding agency type, community size, partnership participation, and effectiveness.

\section{Study measures}

Community size consisted of 4 categories based on the population size served by the agency: 1$)$ very small $(<30,000$ residents), 2) small (30,000-60,000 residents), 3) medium (60,001-100,000 residents), and 4) large ( $\geq 100,001$ residents). Partnership involvement was assessed by asking, "Within the past five years, has your agency/organization partnered with an outside organization (eg, health department, nonprofit, health care organization) to specifically promote health, wellness or physical activity within your community" (yes/no)? The number of partnerships was assessed by asking "With how many different health/wellness partnerships is your organization currently involved?" Two items developed by Hasnain-Wynia et al (8) were used to assess the degree to which their organization recognized the need for health partnerships and had experience with them on a 5-point scale (1, not at all; 3 , somewhat; and 5, a great deal).

Partnership types were measured by a list of 13 partner types represented in the National Physical Activity Plan (9). Types were 1) public health, 2) nonprofit health promotion agencies, 3) hospitals, 4) planning organizations, 5) transportation agencies, 6) health insurance companies, 7) nursing home and assisted living centers, 8) colleges and universities, 9) schools, 10) local businesses, 11) senior services, 12) sports organizations, and 13) corporations.

Perceptions of partnership effectiveness were measured with 12 statements representing factors contributing to partnership effectiveness as established in prior partnership studies $(8,10,11)$. Items assessed included decision making and conflict resolution, leadership and management, shared vision and trust, resource allocation, and communication. Examples of these statements are, "Our health partnership decision making is inclusive," "Our health partnerships have clearly defined goals and objectives," and "Stereotypes about partners from other professions have been broken." They were rated on a 5-point Likert-type scale (1, strongly disagree; 2, disagree; 3, neither agree nor disagree; 4, agree; and 5, strongly agree). Content validity of these items was established in previous research, and authors recommended their use in future partnership studies $(8,10,11)$. Finally, partnership outcomes were measured with the question "To what extent has your agency's/organization's involvement in health partnerships resulted in the following ...”. A 
closed-ended list of outcomes followed and were answered on a 5-point scale (1, not at all; 3, somewhat; and 5, a great deal). The list was 1) leveraging additional resources (eg, money, personnel, equipment), 2) visibility, 3) image, 4) meeting the mission statement, 5) linking to funding opportunities, 6) changes in policy, and 7) improvements to physical features within the community. These items were developed in consultation with NRPA staff and by using themes that emerged from in-depth interviews with park and recreation managers and directors. Frequencies and descriptive statistics were used to describe the characteristics of the sample and their partnership engagement. Chisquare analysis was used to compare characteristics of partnerships by community size, and analysis of variance (ANOVA) was used to compare partnership effectiveness and outcomes by community size.

\section{Results}

Local and municipal park and recreation agencies were most of the sample (892 [81.9\%] organizations). There were also 96 (8.8\%) county park systems and 101 (9.3\%) special districts represented. Regarding community size, 409 (40\%) agencies serve very small communities, 221 (21.6\%) serve small communities, 139 (13.6\%) serve medium communities, and 253 (24.8\%) serve large communities; 67 respondents did not answer the question. Most respondents indicated that their organization engaged in at least 1 health partnership in the last 5 years, with an average of 5 partnerships.

Results indicated that as community size increased, the mean number of health partnerships increased significantly $(F$ $=13.64$, degrees of freedom $[\mathrm{df}]=4, P<.001)$. Also, as community size increased, experience with partnerships increased $(F=9.64, \mathrm{df}=3, P<.001)$. Very small communities (mean, 3.8 ) had significantly less experience with partnerships than both medium (mean, 4.1) and large communities (mean, 4.2). Moreover, very small communities (mean, 3.8) were significantly less likely than large communities (mean, 4.1) to acknowledge the need to develop health partnerships $(F=3.56, \mathrm{df}=3, P=.014)$.

Types of health and wellness partnerships engaged in also significantly varied by community size for 7 of the 13 partner types (Table 1). Very small and large communities partnered significantly more frequently with senior services, nonprofit health promotion agencies, and public health agencies than did small and medium communities. Large and very small communities collaborated with colleges and universities, transportation agencies, and planning organizations more often than did small and medium communities. Finally, large communities most often partnered with corporations, followed by very small communities, small, and medium communities. No differences existed between community size and partnerships with hospitals, nursing homes and assisted living centers, sports organizations, schools, and health insurance companies.

Four of the 12 partnership effectiveness items differed significantly by community size: 1) our health partnership decision making is inclusive, 2) our health partnerships are empowered to make decisions, 3) our health partnerships have clearly defined goals and objectives, and 4) our health partnerships have a strong vision of their mission and purpose (Table 2). Regarding inclusive decision making, small and large communities reported the highest agreement followed by very small and medium communities. Regarding being empowered to make decisions and having clear goals and objectives, large communities agreed the most, followed by small, very small, and medium communities. Finally, large communities were most likely to agree that their health partnerships have a strong mission and coherent vision of their mission. Very small and small communities had the next highest ratings, and medium communities had the lowest ratings. Differences in perceived effectiveness across groups, although significant, were modest.

Four partnership outcomes varied significantly by community size: 1) the extent to which the agency leveraged additional resources because of the partnership, 2) the ability to meet the mission statement, 3) linking to funding opportunities, and 4) making policy changes (Table 3). For all outcomes, the largest communities were more likely to report that their partnership helped them achieve these outcomes. Because outcome ratings increased as community size increased, it appears that large communities have an advantage over very small communities with regard to leveraging partnership outcomes, but these differences were modest.

\section{Discussion}

As community size increased, the number of partnerships and experience with health collaborations also increased. As community size increases, the number of available partners (ie, number and type) is likely to increase as a function of population density; this is especially relevant for rural areas that comprised more than $70 \%$ of the respondents who reported working in very small communities. These findings are consistent with those of Beatty, Harris, and Barnes' (12) partnership study, which indicated that small rural communities had significantly fewer partnerships with nonprofits than suburban and urban health departments. Only $16 \%$ all US nonprofits are in rural areas, compared with $39 \%$ in suburban and $45 \%$ in urban areas (13). Very small communities were significantly less likely to recognize the need for health partnerships. However, as suggested by others $(14,15)$, this may be due to very limited agency budgets (because of lower tax bases), which translate to fewer staff who are spread thin in their duties. In other words, very 
small communities may not recognize the need to partner mainly because they are small and focused on maintaining what they have in place.

Very small and large communities were more likely than small and medium communities to partner with 7 organization types (ie, senior services, nonprofit health promotion agencies, public health agencies, colleges and universities, transportation agencies, planning organizations, and corporations). According to Gazley and Brudney (16), "The motivation to partner is driven by a desire to secure those resources most scarce for the respective sector: expertise and capacity for government, funding for nonprofits" (p. 389). This might be one reason why very small and large communities were more likely to partner with these organization types than small and medium communities. Perhaps large communities are good at recognizing when they need more expertise whereas very small communities are seeking to expand their limited capacity. Among agencies that had not engaged in partnerships during the last 5 years, the reason most frequently cited was not having enough resources to start a partnership. Resources can mean many things to people, and post-hoc analysis of open ended comments indicated that lack of staff and time and limited funding were the most common challenges to starting partnerships.

Large communities had the highest ratings of effectiveness for all 4 items (ie, inclusive decision making, empowerment to make decisions, clearly defined goals and objectives, strong vision of their mission); medium communities had the lowest ratings for 3 effectiveness items. Evidence supports the idea that clearly defined goals are particularly important to effective partnerships (17-19). For example, Gazley and Brudney (16) suggested that one reason that larger public agencies engage in partnerships is to better leverage the shared goals of the various partners. Also, it is plausible that large communities have more effective partnerships than small communities. Our data indicated that large communities were more likely to recognize the need for partnerships and they reported more experience with them. The literature suggests that having good communication at all levels, building trust, developing shared goals and values, and cooperating through coordinated actions are all important to the effectiveness of partnerships (18). Thus, it is possible that the more experience agencies or managers have with partnerships, the better able they are to meet the above effectiveness criteria.

Large communities were significantly more likely to leverage additional resources and meet their mission statement as a result of their participation in partnerships. This may be attributed to their involvement with more partnerships than smaller communities and their ability to leverage the additional resources available as a result of those partnerships. Very small communities were significantly less likely to link to funding opportunities because of their limited partnership involvement. An ongoing challenge for rural areas is that little funding is channeled to them compared with urban and suburban communities. Only $0.2 \%$ of foundation funding in the United States is awarded to small rural communities (20). Often, the smallest rural communities have organizations with few staff, sometimes only part-time, and less specialized, thereby limiting their capacity to pursue grants, sponsorships, and other funding opportunities (12). Also, according to Mays and Scutchfield (21), smaller communities often have few organizations in their communities to address health needs compared with larger communities that have more decentralized governance, which results in partnerships that are more entrepreneurial. The literature on barriers that limit partnerships supports the assertion that smaller agencies might experience more challenges with partnership development and management than larger ones. For example, barriers reported by respondents in a study by Brownson et al (22) were bureaucracy, interorganizational policies, lack of time, differing organizational goals, challenges finding collaborators, and the costs of partnering outweighing the benefits. Moreover, Kegler et al (23) suggested that turf issues and competition were also issues of concern regarding limited resources and budget concerns.

The differences in effectiveness and outcomes related to partnerships might also be about leadership. According to Bryson et al (24), "the leadership challenge in cross-sector collaboration may be viewed as a challenge of aligning initial conditions, processes, structures, governance, contingencies and constraints, outcomes, and accountabilities such that good things happen in a sustained way over time - indeed, so that public value can be created" (p. 52). In our sample, respondents who work in large communities had the most years of work experience in their agency. It is likely that directors with more experience are better equipped to face the challenges presented when creating and managing partnerships. Kegler et al (23) suggested that it takes a special type of leader to successfully create and manage partnerships: a boundary leader. They asserted that boundary leaders are people who can skillfully negotiate the spaces between organizations. Moreover, Tower et al (17) posited that a feature of successful partner relationships is complementary expertise and knowledge among the players in the partnership.

One of the limitations of this study is that we did not explicitly define the concept of "partnership" for respondents. Therefore, various partnership types (ie, short, long-term, formal, and informal) were likely reported on. Nevertheless, Cousens et al (25) reported that "regardless of the type or pattern of linkage, participants identified their relationships as a partnership" (p. 32) and that it appeared to be a "broadly encompassing phrase used to indicate an external linkage" (p. 42). As a next step, it would be useful to better understand the essential elements of different types of partnerships between community parks and recreation and health organizations. For example, does effectiveness vary depending on how long the partnership has existed, the complexity and number of organizations involved in the partnership, or by the sectors involved in the partnership? These questions are important to answer as community 
park and recreation agencies continue to engage in health partnerships. Our findings describe some differences that exist in partnerships by community size; however, the mechanisms that facilitate perceptions of partnership effectiveness and outcomes remain unclear. Partnership practices should be examined to better understand the processes that shape the effectiveness and outcomes of these health partnerships.

Despite these limitations, some differences regarding partnership practices, effectiveness, and outcomes were revealed among different sizes of communities. These findings indicate that smaller communities (which are most likely rural) are disadvantaged regarding their ability to develop and implement partnerships with health organizations. This is especially troubling since poverty, obesity, chronic disease, and uninsured rates are higher in rural areas than suburban and urban areas $(26,27)$. Not only do very small communities engage in partnership less, they have fewer organizations to partner with and they must serve a significantly larger geographic area (49.1 miles for rural vs 0.5 miles in urban areas) (28). Moreover, their partnerships were less effective than those of larger communities and they were less able to leverage additional resources and funding from their partnerships. Thus, there is a need to focus on increasing the partnership education and training efforts for park and recreation agencies in small towns and rural communities. Simultaneously, rural advocacy organizations could work with foundations and government agencies to raise awareness of the critical need for resources that will facilitate effective partnerships between community parks and recreation and health organizations. These efforts should improve agencies' abilities to develop and maintain partnerships that more effectively impact public health goals.

\section{Acknowledgments}

The authors would like to thank the National Recreation Foundation for their generous grant support and Kathy Spangler, who has spent more than 25 years advocating for community parks and recreation's role in health and wellness.

\section{Author Information}

Corresponding Author: Laura L. Payne, PhD, University of Illinois Urbana-Champaign, Department of Recreation, Sport and Tourism, 104 Huff Hall, MC-584, 1206 S. Fourth St, Champaign, IL 61820. Telephone: 217-244-7038. Email: lpayne@illinois.edu.

Author Affiliations: Jo An Zimmermann, Texas State University at San Marcos, San Marcos, Texas; Andrew J. Mowen, Geoffrey C. Godbey, Pennsylvania State University, University Park, Pennsylvania; Elizabeth Orsega-Smith, University of Delaware, Newark, Delaware.

\section{References}

1. Kernaghan K. Partnership and public administration: Conceptual and practical considerations. Can Public Adm 1993;36(1):57-76. CrossRef 䍐

2. Mowen AJ, Kerstetter DL. Introductory comments to the special issue on partnerships: partnership advances and challenges facing the park and recreation profession. J Park Recreat Admi 2006;24(1):1-6.

3. Sallis JF, Story M, Orleans CT. A research perspective on findings from Bridging the Gap. Am J Prev Med 2007;33 (4 Suppl):S169-71. CrossRef 国 PubMed 国

4. Bors P, Dessauer M, Bell R, Wilkerson R, Lee J, Strunk SL. The Active Living by Design national program: community initiatives and lessons learned. Am J Prev Med 2009;37(6 Suppl 2):S313-21. CrossRef 园 PubMed 圈

5. CDC's Healthy Communities program. ACHIEVE communities. Atlanta (GA): Centers for Disease Control and Prevention; 2009. http://www.cdc.gov/healthycommunitiesprogram/communities/achieve/. Accessed June 5, 2013.

6. Bocarro JN, Casper J, Henderson KA, Floyd MF, Moore R, Kanters MA, et al. Physical activity promotion in North Carolina: perceptions of public park and recreation directors. J Park Recreat Admi 2009;27(1):1-16.

7. Mowen AJ, Payne LL, Orsega-Smith E, Godbey GC. Assessing the health partnership practices of park and recreation agencies: findings and implications from a national survey. J Park Recreat Admi 2009;27(3):116-31.

8. Hasnain-Wynia R, Sofaer S, Bazzoli GJ, Alexander JA, Shortell SM, Conrad DA, et al. Members' perceptions of community care network partnerships' effectiveness. Med Care Res Rev 2003;60(4, Suppl):40S-62S. CrossRef 圈 PubMed 圈

9. National Physical Activity Plan. Atlanta (GA): Centers for Disease Control and Prevention; 2010. http://www.physicalactivityplan.org/. Accessed April 12, 2007.

10. Selin S, Myers N. Correlates of partnership effectiveness: the coalition for unified recreation in the eastern Sierra. J Park Recreat Admi 1995;13(4):37-46. 
11. Waddock SA, Bannister BD. Correlates of effectiveness and partner satisfaction in social partnerships. Journal of Organizational Change Management 1991;4(2):64-79. CrossRef 圈

12. Beatty K, Harris JK, Barnes PA. The role of interorganizational partnerships in health services provision among rural, suburban, and urban local health departments. J Rural Health 2010;26(3):248-58. CrossRef 国 PubMed 圈

13. Neuhoff A, Dunckleman A. Small but tough: nonprofits in rural America. Boston (MA): The Bridgespan Group; 2011. http://www.bridgespan.org/getattachment/d864f3f7-7e41-404f-aa21-32c596bdb7d6/Small-but-ToughNonprofits-in-Rural-America.aspx. Accessed January 18, 2013.

14. Barnidge EK, Radvanyi C, Duggan K, Motton F, Wiggs I, Baker EA, et al. Understanding and addressing barriers to implementation of environmental and policy interventions to support physical activity and healthy eating in rural communities. J Rural Health 2013;29(1):97-105. CrossRef 囷 PubMed 圈

15. Schaumleffel N, Payne LL. Rural recreation and park development. Parks and Recreation 2010;45(5):33-7.

16. Gazley B, Brudney JL. The purpose (and perils) of government-nonprofit partnerships. Nonprofit and Voluntary Sector Quarterly 2007;36(3):389-415. CrossRef 圈

17. Tower J, Jago L, Deery M. Relationship marketing and partnerships in not-for-profit sport in Australia. Sport Marketing Quarterly 2006;15(3):167-80.

18. Tower JR. An analysis of the relationships between sport associations and sport venues in Victoria [doctoral thesis]. Melbourne (AU): Victoria University; 2008.

19. Baily SBC. Focusing on solid partnerships across multiple sectors for population health improvement. Prev Chronic Dis 2010;7(6):A115. http://www.cdc.gov/pcd/issues/2010/nov/10_0126.htm. Accessed August 4, 2012. PubMed 圈

20. Nonprofit leadership in the rural South: a regional study of executive transition and next generation leadership. Ashville (NC): Rural Support Partners; 2011. http://www.ruralsupportpartners.com/docs/FullReport-

NonprofitLeadershipinthe RuralSouthFinalDraft.pdf. Accessed January 19, 2013.

21. Mays GP, Scutchfield FD. Improving public health system performance through multiorganizational partnerships. Prev Chronic Dis 2010;7(6):A116. http://www.cdc.gov/pcd/issues/2010/nov/10_oo88.htm. Accessed August 4, 2012. PubMed 圈

22. Brownson RC, Parra DC, Dauti M, Harris JK, Hallal PC, Hoehner C, et al. Assembling the puzzle for promoting physical activity in Brazil: a social network analysis. J Phys Act Health 2010;7(Suppl 2):S242-52. PubMed 圈

23. Kegler MC, Hall SM, Kiser M. Facilitators, challenges, and collaborative activities in faith and health partnerships to address health disparities. Health Educ Behav 2010;37(5):665-79. CrossRef圈 PubMed 圈

24. Bryson JM, Crosby BC, Middleton Stone M. The design and implementation of cross-sector collaborations: propositions from the literature. The design and implementation of cross-sector collaborations: propositions from the literature.Public Administration Review 2006;66(Dec 2006 Special issue):44-55.

25. Cousens L, Barnes M, Stevens J, Mallen C, Bradish C. Who's your partner? Who's your ally? Exploring the characteristics of public, private, and voluntary recreation linkages. J Park Recreat Admi 2006;24(1):32-55.

26. Blumenthal SJ, Kagen J. The effects of socioeconomic status on health in rural and urban America. JAMA 2002;287(1):109. CrossRef 圈 PubMed 圈

27. What's different about rural health care? Washington (DC): National Rural Health Association. http://www.ruralhealthweb.org/go/left/about-rural-health. Accessed January 20, 2013.

28. Fanburg S. Rural nonprofits lag on revenue, access. The NonProfit Times; 2011. http://www.thenonprofittimes.com/article/detail/rural-nonprofits-lag-on-revenue-access-4178. Accessed January 19, 2013.

\section{Tables}

Table 1. Chi-Square Analysis for Types of Partnerships Engaged in by Community Parks and Recreation, by Community Sizea, 2007

\begin{tabular}{|c|c|c|c|c|c|}
\hline Partner Type, n (\%) & $\begin{array}{c}\text { Very Small, } n \\
(\%)\end{array}$ & $\underset{(\%)}{S m a l l, ~} n$ & $\begin{array}{l}\text { Medium, } n \\
(\%)\end{array}$ & $\begin{array}{c}\text { Large, } n \\
(\%)\end{array}$ & $X^{2}\left(\begin{array}{c}d f=3), P \\
\text { Value }\end{array}\right.$ \\
\hline Senior services & $145(33.8 \%)$ & $100(23.3 \%)$ & $64(14.9 \%)$ & $120(28.0 \%)$ & $7.61, P=.05$ \\
\hline $\begin{array}{l}\text { Nonprofit health promotion } \\
\text { agencies }\end{array}$ & $170(33.3 \%)$ & $112(22.0 \%)$ & $77(15.1 \%)$ & $151(29.6 \%)$ & $14.57, P=.002$ \\
\hline
\end{tabular}




\begin{tabular}{|l|r|r|r|r|r|}
\hline Partner Type, n (\%) & $\begin{array}{c}\text { Very Small, n } \\
\mathbf{( \% )}\end{array}$ & $\begin{array}{c}\text { Small, } \mathbf{n} \\
\mathbf{( \% )}\end{array}$ & $\begin{array}{c}\text { Medium, n } \\
\mathbf{( \% )}\end{array}$ & $\begin{array}{c}\text { Large, } \mathbf{n} \\
\mathbf{( \% )}\end{array}$ & $\begin{array}{c}\left.\mathbf{X}^{\mathbf{2}} \mathbf{( d f}=\mathbf{3}\right), \boldsymbol{P} \\
\text { Value }\end{array}$ \\
\hline Public health agencies & $204(35.4 \%)$ & $124(21.5 \%)$ & $81(14.1 \%)$ & $167(29.0 \%)$ & $16.37, P=.001$ \\
\hline Colleges and universities & $88(28.6 \%)$ & $59(19.2 \%)$ & $54(17.5 \%)$ & $107(34.7 \%)$ & $32.81, P<.001$ \\
\hline Transportation agencies & $44(26.5 \%)$ & $38(22.9 \%)$ & $22(13.3 \%)$ & $62(37.4 \%)$ & $18.82, P<.001$ \\
\hline Planning organizations & $47(27.0 \%)$ & $42(24.1 \%)$ & $25(14.4 \%)$ & $60(34.5 \%)$ & $14.57, P=.002$ \\
\hline Corporations & $44(22.6 \%)$ & $37(19.0 \%)$ & $30(15.4 \%)$ & $84(43.1 \%)$ & $47.49, P<.001$ \\
\hline
\end{tabular}

a Community size was defined as 1 ) very small (<30,000 residents), 2 ) small $(30,000-60,000$ residents), 3 ) medium (60,001-100,000 residents), and 4$)$ large ( $\geq 100,001$ residents).

Table 2. Analysis of Variance for Mean Differences in Effectiveness of Community Parks and Recreation Partnerships, by Community Sizea, 2007

\begin{tabular}{|l|r|r|r|r|r|}
\hline Effectiveness Item & $\begin{array}{c}\text { Very Small, } \\
\text { Mean (SD) }\end{array}$ & $\begin{array}{c}\text { Small, } \\
\text { Mean (SD) }\end{array}$ & $\begin{array}{c}\text { Medium, } \\
\text { Mean (SD) }\end{array}$ & $\begin{array}{c}\text { Large, } \\
\text { Mean (SD) }\end{array}$ & $\begin{array}{l}\boldsymbol{F}(\mathbf{d f}=\mathbf{3}), \\
\boldsymbol{P} \text { Value }\end{array}$ \\
\hline Partnership decision making is inclusive & $3.4(0.8)$ & $3.5(0.8)$ & $3.3(0.9)^{\mathrm{b}}$ & $3.6(0.8)^{\mathrm{b}}$ & $\begin{array}{r}2.80, P \\
=.03\end{array}$ \\
\hline $\begin{array}{l}\text { Partnerships are empowered to make } \\
\text { decisions }\end{array}$ & $3.5(0.8)$ & $3.6(0.7)$ & $3.4(0.9) \mathrm{b}$ & $3.6(0.8) \mathrm{b}$ & $\begin{array}{r}3.74, P \\
=.01\end{array}$ \\
\hline $\begin{array}{l}\text { Partnerships have clearly defined goals } \\
\text { and objectives }\end{array}$ & $3.3(0.8) \mathrm{b}$ & $3.4(0.9)$ & $3.2(0.8)^{\mathrm{b}}$ & $3.5(0.9)^{\mathrm{b}}$ & $\begin{array}{r}4.18, P \\
=.008\end{array}$ \\
\hline $\begin{array}{l}\text { Partnerships have a strong vision of their } \\
\text { mission statement and purpose }\end{array}$ & $3.4(0.8)$ & $3.4(0.8)$ & $3.3(0.8)^{\mathrm{b}}$ & $3.6(0.8)^{\mathrm{b}}$ & $\begin{array}{r}2.67, P \\
=.04\end{array}$ \\
\hline
\end{tabular}

a Community size was defined as 1 ) very small ( $<30,000$ residents), 2 ) small (30,000-60,000 residents), 3) medium (60,001-100,000 residents), and 4$)$ large ( $\geq 100,001$ residents). Answers were rated on a 5-point Likert-type scale ( $1=$ strongly disagree, 2 = disagree, $3=$ neither agree nor disagree, $4=$ agree, and $5=$ strongly agree).

b Indicates significant group differences from the Tukey's post-hoc tests.

Table 3. Analysis of Variance for Mean Differences in Community Parks and Recreation Partnership Outcomes, by Community Sizea, 2007

\begin{tabular}{|l|r|r|r|r|r|}
\hline Outcome & \multicolumn{1}{|c|}{$\begin{array}{c}\text { Very Small, } \\
\text { Mean (SD) }\end{array}$} & $\begin{array}{c}\text { Small, } \\
\text { Mean (SD) }\end{array}$ & $\begin{array}{c}\text { Medium, } \\
\text { Mean (SD) }\end{array}$ & $\begin{array}{c}\text { Large, } \\
\text { Mean (SD) }\end{array}$ & $\begin{array}{r}\boldsymbol{F} \text { (df = 3), P } \\
\text { Value }\end{array}$ \\
\hline $\begin{array}{l}\text { Extent to which the agency could } \\
\text { leverage additional resources }\end{array}$ & $3.2(1.1)^{\mathrm{b}}$ & $3.5(1.1)$ & $3.5(1.1)$ & $3.6(1.1)^{\mathrm{b}}$ & $\begin{array}{r}5.62, P \\
=.001\end{array}$ \\
\hline Ability to meet the mission statement & $3.6(1.1)^{\mathrm{b}}$ & $3.7(.8)$ & $3.7(1.0)$ & $3.9(1.0)^{\mathrm{b}}$ & $\begin{array}{r}5.06, P \\
=.002\end{array}$ \\
\hline Linking to funding opportunities & $3.1(1.1) \mathrm{b}$ & $3.2(1.0)$ & $3.3(1.2)$ & $3.5(1.0) \mathrm{b}$ & $\begin{array}{r}5.12, P \\
=.002\end{array}$ \\
\hline Making changes in policy & $2.3(1.1)^{\mathrm{b}}$ & $2.6(1.1)$ & $2.6(1.1)$ & $2.7(1.1)^{\mathrm{b}}$ & $\begin{array}{r}4.44, P \\
=.004\end{array}$ \\
\hline
\end{tabular}

a Community size was defined as 1 ) very small ( $<30,000$ residents), 2$)$ small $(30,000-60,000$ residents), 3$)$ medium (60,001-100,000 residents), and 4$)$ large ( $\geq 100,001$ residents). Answers were rated on a 5-point Likert-type scale $(1=$ not at all, $3=$ somewhat, and $5=$ a great deal).

b Indicates significant group differences from the Tukey's post-hoc tests. 
Department of Health and Human Services, the Public Health Service, the Centers for Disease Control and Prevention, or the authors' affiliated institutions.

5 The RIS file format is a text file containing bibliographic citations. These files are best suited for import into

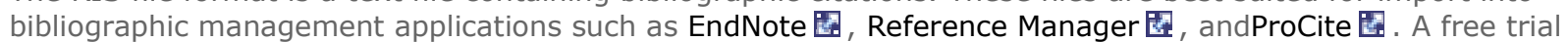
download is available at each application's web site.

For Questions About This Article Contact pcdeditor@cdc.gov

Page last reviewed: July 25, 2013

Page last updated: July 25, 2013

Content source: National Center for Chronic Disease Prevention and Health Promotion

Centers for Disease Control and Prevention 1600 Clifton Rd. Atlanta, GA 30333, USA

8oo-CDC-INFO (80o-232-4636) TTY: (888) 232-6348 - Contact CDC-INFO

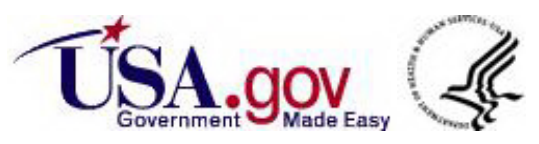

